\section{The Effect of Fertilizer Level and Foliar-applied Calcium on Seed Production and Germination of Gerbera hybrida}

\author{
Christian Andreasen ${ }^{1}$, Andrius Hansen Kemezys, and Renate Müller \\ Department of Plant and Environmental Sciences, Faculty of Science, \\ University of Copenhagen, Højbakkegaard Allé 13, DK 2630 Taastrup, \\ Denmark
}

Additional index words. germination curves, ornamental plants, potted plants, seed propagation, seed quality

\begin{abstract}
Gerbera hybrida is an ornamental plant of great commercial interest, which is primarily propagated by seeds. We investigated whether increasing fertilizer concentrations during seed set enhanced plant biomass, number of flower heads, seed set, and seed weight. Furthermore, we studied whether an additional foliar calcium application influenced the same parameters. Subsequently, the effect of the various treatments on the germination of the obtained seeds was explored. Two identical experiments (A and B) were carried out with five concentrations of nutrient solutions corresponding to an electrical conductivity (EC) of $1.25 \mathrm{mS} \cdot \mathrm{cm}^{-1}, 2.50 \mathrm{mS} \cdot \mathrm{cm}^{-1}, 3.75$ $\mathrm{mS} \cdot \mathrm{cm}^{-1}, 5.00 \mathrm{mS} \cdot \mathrm{cm}^{-1}$, and $6.25 \mathrm{mS} \cdot \mathrm{cm}^{-1}$. Additionally, plants were sprayed with a $0.5 \%$ foliar-applied calcium solution or deionized water (control) three times during the experimental period. In Expt. A, the concentration of fertilizer significantly affected seed production. Number of flower heads and seed weight were not influenced by the dose of fertilizer, but plant biomass and number of seeds were significantly reduced at the highest concentration $\left(6.25 \mathrm{mS} \cdot \mathrm{cm}^{-1}\right)$. In Expt. B, the fertilizer concentration did not affect number of flower heads and seed number, but seed weight and plant biomass were significantly reduced at the highest fertilizer concentration. In both experiments, the seeds germinated slower and less seeds germinated when plants had received the largest amount of fertilizer $\left(6.25 \mathrm{mS} \cdot \mathrm{cm}^{-1}\right)$. In none of the experiments did applied calcium affect the number of flowers, seed production, seed weight, or the total biomass. Our data indicate that seed producers of $G$. hybrida should not apply standard fertilizer in a concentration higher than corresponding to an $\mathrm{EC}$ of $\approx 1.25 \mathrm{mS} \cdot \mathrm{cm}^{-1}$. It would have been valuable if we also had included a treatment with a lower EC value like $0.75 \mathrm{mS} \cdot \mathrm{cm}^{-1}$ to improve the estimate of the optimal EC level from a curved function for the seed production and quality parameters.
\end{abstract}

Gerbera species are ornamental plants of considerable economic importance produced in many parts of the world. The genus belongs to the sunflower family (Asteraceae) and is widely used as a potted ornamental plant as cut a flower and less often as a decorative garden plant. Gerbera jamesonii, a perennial herb, was introduced from South Africa into Europe and the United States in the 19th century (Albino-Garduño et al., 2008). From this point, selection and improvement toward better cultivars started and plant breeders have developed lines for cut flower production, potted plants for indoor use, and to a limited extent for bedding and

Received for publication 22 Jan. 2014. Accepted for publication 2 Mar. 2014.

We thank Freddie Skov-Hundevad, Sakata Ornamentals Europe A/S, Langeskov, Denmark, for providing plants and participating in the planning of the experiments.

${ }^{1}$ To whom reprint requests should be addressed; e-mail can@plen.ku.dk. et al., 1990). High seed quality and uniform germination in various seed batches are essential for growers of ornamental plants, especially because of increasing automation in sowing practices. Consequently, seed companies are interested in identifying critical factors that influence seed production and determine seed quality, but they are at the same time interested in reducing production costs as much as possible and optimize the use of resources (e.g., fertilizer).

Occasionally seed producers experience big differences in seed set and quality among different batches. Reasons for the differences may be humidity, nutrient or water status as well as climate factors during growth of the mother plants. Climate factors and humidity during pollination may also have an impact on fertilization and subsequent seed set. Little is known about factors influencing Gerbera seed set, storage, and germination (Carpenter et al., 1995). In a greenhouse study, it was demonstrated that fertilizer use in the production of potted Gerbera could be reduced by $50 \%$ without a negative impact on leaf area, flower head number and appearance, and total plant total dry weight (Zheng et al., 2004). In a field production study, different levels of nitrogen and potassium fertility did not negatively influence flower size and quality (Dufault et al., 1990). Paradiso et al. (2003) evaluated the response of two Gerbera cultivars to EC level of a nutrient solution on 1 -year plants fertigated with two EC values, $1.6 \mathrm{dS} \cdot \mathrm{m}^{-1}$ and $2.4 \mathrm{dS} \cdot \mathrm{m}^{-1}$, at $\mathrm{pH}$ 6.0. Flower production increased in plants fertigated with $2.4 \mathrm{dS} \cdot \mathrm{m}^{-1}$ solution compared with those under $1.6 \mathrm{dS} \cdot \mathrm{m}^{-1}(+16 \%)$ and stem thickness and fresh weight of flowers were higher. Higher EC level increased also nutrient uptake, plant development $(+9 \%$ in leaf area), and water consumption $(+11 \%)$. However, there was no information in the studies about how fertilizer levels or composition affects seed set or subsequent germination of the produced seed. In Primula vulgaris, potassium has been identified to have influence on seed quality. Increasing seed potassium concentration was negatively correlated with germination capacity in randomly selected batches of commercial seeds (Zerche et al., 2007). Additionally, calcium appears to be a determinant of seed quality. Foliar-applied calcium can have a positive effect on seed set and quality on some ornamental plant species, e.g., Indian gooseberry (Emblica officinalis) (Shukla, 2011) and Petunia (Santos et al., 2009).

In the present study we hypothesized that 1) an increase in fertilizer level during seed set of Gerbera hybrida results in increasing biomass production and flower head number, improves seed set, and enhances seed weight; 2) an additional foliar calcium application will furthermore increase seed set and enhance seed weight; and 3) an increasing fertilizer level will affect the germination speed and germination percentage. We tested these hypotheses by conducting two independent greenhouse experiments. 


\section{Materials and Methods}

Plant material and growing conditions. Plants of Gerbera hybrida 'Gerbera Festival Rose' from the F1 generation were used in the experiments and delivered by Sakata Ornamentals Europe A/S, Odensevej 82, Marslev, Denmark. The cultivar is characterized by being robust, uniform, and having pink flowers. The Gerbera seeds were sown in Week 22. The plants were delivered to the University of Copenhagen when they were 5 weeks old. In Week 27, plants were replanted into 2 -L pots (diameter $17 \mathrm{~cm}$ ) in a peat soil mixture, "Pindstrup mixture no. 1" (Pindstrup Mosebrug A/S, Ryomgaard, Denmark). The base was blonde peat ( $\mathrm{pH} 5.5)$; dry matter content was 55 to $75 \mathrm{~g} \cdot \mathrm{L}^{-1}$; and nitrogenphosphorus-potassium fertilizer per $\mathrm{m}^{3}$ was $0.650 \mathrm{~kg} \cdot \mathrm{m}^{-3}$. This very low nutrient content in the substrate was intended to function as a basic supply. The different concentrations of the liquid fertilizer given with each watering were the treatments in this experiment.

Experimental design and treatments. Two independent and identical experiments (Expts. $\mathrm{A}$ and $\mathrm{B}$ ) were placed in the same greenhouse but spaced by 1 week. Five different concentrations of liquid fertilizer were applied and combined with or without a foliar calcium treatment, resulting in a total of 10 treatments. A 300-L liquid stock solution of fertilizer

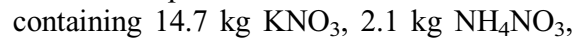
$1.95 \mathrm{~kg} \mathrm{Ca}\left(\mathrm{NO}_{3}\right)_{2}, 0.5 \mathrm{~L}$ iron chelate $(5.2 \%)$, $2.8 \mathrm{~L}$ phosphoric acid (72\%), and 4.5 L Micropioner (Azelis, Antwerp, Belgium) was diluted to five concentrations of nutrient solutions with an $\mathrm{EC}$ of $1.25 \mathrm{mS} \cdot \mathrm{cm}^{-1}, 2.50 \mathrm{mS} \cdot \mathrm{cm}^{-1}, 3.75$ $\mathrm{mS} \cdot \mathrm{cm}^{-1}, 5.00 \mathrm{mS} \cdot \mathrm{cm}^{-1}$, and $6.25 \mathrm{mS} \cdot \mathrm{cm}^{-1}$, respectively. The water used for preparation of the fertilizer solutions was deionized water. We adjusted the $\mathrm{pH}$ value of the nutrient solution to 6 by adding phosphoric acid or sodium hydroxide. Plants were watered solely with a nutrient solution of the five levels throughout the production period. In addition, plants were either sprayed with a $0.5 \%$ calcium solution or with deionized water as a control. The calcium solution was prepared by mixing dehydrated calcium chloride with deionized water. The foliar spray treatment was repeated three times with an interval of $15 \mathrm{~d}$. The calcium treatments were performed in Weeks 33, 35 and 37, respectively, just before the plants developed flowers. The foliar calcium treatment was performed using a 1-L hand sprayer. Plants were sprayed five times from different sides, resulting in $\approx 3 \mathrm{~mL}$ calcium solution per plant.

Within experiments, each of the 10 treatments comprised three replicates each with six plants. The replicates were placed on three adjacent tables; the six plants per replicate were placed randomly on the tables. The total numbers of plants in each experiment were:

$$
\begin{aligned}
& 10 \text { (treatments }) \times 3(\text { replicates }) \\
& \quad \times 6 \text { (plants per replicate })=180 \text { plants } .
\end{aligned}
$$

Thirty-six plants surrounded the experiment on each table to avoid an edge effect.
Treatments were completely randomized within each replicate. The plants were watered manually with the same amount of nutrient solution at a time throughout all treatments. The plants were usually watered with $300 \mathrm{~mL}$ fertilizer solution at a time with 2 to $4 \mathrm{~d}$ between watering. Each pot was placed on a plastic plate to keep excess water, which was absorbed by the plants subsequently. The 36 surrounding plants were automatically drip-irrigated with a standard nutrient solution. When the experiments were finished in December, samples of nutrient solutions were squeezed out of the soil and the EC was measured to elucidate if accumulation of fertilizers had occurred during the growing season.

Pollination. Flower heads were pollinated using a brush. One brush was used for pollinating plants from the same treatment. Pollen were collected from anthers of one plant using a brush and evenly distributed on another plant's stigmata. Pollen, which was collected from one plant, was never used to pollinate the same plant to avoid selfpollination. Each flower was pollinated twice to optimize the pollination. After pollination, the brushes were dipped into $80 \%$ ethyl alcohol for cleaning.

Seed harvesting and germination. With 2 to 4-d intervals, plants were inspected and seeds harvested. Petals were removed when they turned pale and loosened up. The seeds were harvested when the seeds inside the flower became mature and when the seeds loosened up from the flower base. The seeds were harvested by pulling them up by hand and were stored in paper bags. Seeds from different plants were harvested separately, but if one plant had more than one flower with mature seeds, seeds were put in the same bag and the number of flowers per plant was noted. Each plant's identification number, date, and number of flowers per plant were noted on the bag. The bags with seeds were placed in a drying room shortly after harvest at a temperature of $20{ }^{\circ} \mathrm{C}$ and a relative humidity of $30 \%$. The total number of seeds per plant was counted and the total seed weight determined. One thousand seed weights were calculated for each replicate. Seed germination tests of 50 seeds were done in a Jacobsen's apparatus (ISTA, 2011) at $20{ }^{\circ} \mathrm{C}$ with four replicates.

Control of pests and diseases. The plants were generally healthy and developed normally. However, some pests and diseases occurred during the experiment and pest and disease control were necessary. After replanting, the pots were watered with deionized water containing VectoBac 12AS (Valent BioSciences Corporation, Libertyville, IL), an aqueous suspension formulation of Bacillus thuringiensis subsp. israelensis (strain AM65-52), which is a microbial pesticide used to control larvae of Bradysia ssp. Treatment with Vectobac was repeated 1 week later. Besides treatment with Vectobac $12 \mathrm{AS}$, the following natural insect enemies were used to control aphids, thrips, and leafminer flyes: Aphidius colemani Aphidius ervi,
Amblyseius swirskii, Orius majusculus, and Diglyphus isaea. Furthermore, two insecticides pirimicarb (Pirimor G; Syngenta) and imidacloprid (Confidor WG 70; Bayer) were applied several times to control aphids late in the experiment.

Biomass measurements. When the experiments were ended, the above-ground biomass of the plants was harvested, placed in perforated plastic bags, and dried in a drying chamber at $80{ }^{\circ} \mathrm{C}$ for $24 \mathrm{~h}$ and subsequently weighed.

Statistical methods. The two experiments were analyzed separately. Statistical analyses were performed using the opensource program R Version 2.11 .1 (<http:// www.R-project.org $>$ ). A linear model was used to investigate the effect of the fertilizer dose, calcium application, and the interaction effects on the number of flower heads, seed production, seed weight, and biomass production, respectively. $P$ values $<0.05$ were considered significant. The models were reduced because calcium did not show any significant effect. Homogeneity of variance was assessed on the basis of plots of standardized residuals against predicted values by use of residual plots and QQ normal plots of raw residuals. A single-step procedure incorporates correlation between tests when calculating the adjusted $P$ values between means of treatments (Hothorn et al., 2008).

The seed germination was modeled using a cumulative distribution function of the standard log-logistic distribution:

$$
F(t)=\frac{d}{1+\exp \left[b\left\{\log (t)-\log \left(t_{50}\right)\right\}\right]}
$$

The upper limit parameter $d$ denotes the proportion of seeds that germinated during the experiment out of the total number of seed present at the beginning of the experiment and as such is a unitless probability. The parameter $b$ is proportional to the slope of $F$ at time $t$ equal to the parameter $t_{50}$ where $50 \%$ of the seeds that germinated during the experiment have germinated. The parameter $t_{50}$ has the same unit as the time scale considered in the experiment. The estimation and model checking procedures are based on treating the data as event times, that is, to record the time it takes for germination (the event of interest) to occur as described by Ritz et al. (2013). Based on $T_{50}$ values and their variance, weighed linear regression (Draper and Schmidt, 1966) was performed to show relation between fertilizer level and time to $50 \%$ germination.

\section{Results}

Expt. A. The mean number of flowers was 4.02 per plant $(\mathrm{SD}=1.51)$. The number of flowers was not significantly affected by fertilizer level and foliar-applied calcium, and there was no interaction effect. The mean number of seeds per plant was significantly affected by fertilizer dose $(P=0.0203)$ (Fig. 1A). An analysis of variance (ANOVA) showed that the reduced model (without calcium) described the data just as good as 
the model including calcium. Homogeneity of variance was checked on the basis of plots of standardized residuals against predicted values by use of residual plots and QQ normal plots of raw residuals. Figure $1 \mathrm{~A}$ indicated that it might be reasonable to describe the data by a second-order polynomial model (not shown). The model exhibited significance for all parameters. Based on this model, the maximum seed production can be obtained by using a nutrient solution with an EC of $\approx 3 \mathrm{mS} \cdot \mathrm{cm}^{-1}$. Calculation of the adjusted $P$ values between means of treatments revealed that the seed production at a fertilizer concentration corresponding to $6.25 \mathrm{mS} \cdot \mathrm{cm}^{-1}$ was significantly lower than the seed production at the other concentrations except 1.25 $\mathrm{mS} \cdot \mathrm{cm}^{-1}$ [hypotheses: $6.25-2.5=0(P=$ $0.0016) ; 6.25-3.75=0(P=0.01052)$; $6.25-5=0(P=0.00368)]$. The seed production at the other concentrations did not differ significantly from each other (Fig. 1A). The average thousand seed weight was $3.196 \mathrm{~g}$ ( $\mathrm{SD}=0.752 \mathrm{~g}$ ). The thousand seed weight was not significantly affected by fertilizer level or calcium application (Fig. 1C). The dry biomass production was significantly affected by fertilizer level $(P=0.0019)$ but not by calcium application (Fig. 1E). An ANOVA showed that the reduced model (without calcium) described the data just as good as the model including calcium. Homogeneity of variance was checked based on plots of standardized residuals against predicted values by use of residual plots and QQ normal plots of raw residuals. The calculations of the adjusted $P$ values between means of treatments exhibited that dry biomass production at a fertilizer concentration of $6.25 \mathrm{mS} \cdot \mathrm{cm}^{-1}$ was significantly lower than the biomass production at the $2.5 \mathrm{mS} \cdot \mathrm{cm}^{-1}$ $(P=0.001)$. The biomass production at the other fertilizer levels did not significantly differ from each other (Fig. 1E). The germination curves indicated that increasing fertilizer levels had a negative influence on the number of germinated seeds and germination speed (Fig. 2; Table 1). This is most obvious for the highest dose $\left(6.25 \mathrm{mS} \cdot \mathrm{cm}^{-1}\right)$. Applied calcium did not significantly affect the germination.

At the end of the experiment, we measured the EC in 10 samples of nutrient solutions squeezed out of the soil. Five samples were taken from pots where plants had been sprayed with calcium and five from pots that did not receive calcium. The samples exhibited an EC of $2.95 \mathrm{mS} \cdot \mathrm{cm}^{-1}, 8.65$ $\mathrm{mS} \cdot \mathrm{cm}^{-1}, 9.96 \mathrm{mS} \cdot \mathrm{cm}^{-1}, 15.71 \mathrm{mS} \cdot \mathrm{cm}^{-1}$, and $23.20 \mathrm{mS} \cdot \mathrm{cm}^{-1}$, respectively, which was clearly higher than the original given concentrations. The EC in water samples squeezed out of the soil from five pots irrigated with a fertilizer solution with EC of $2.15 \mathrm{mS} \cdot \mathrm{cm}^{-1}, 2.5 \mathrm{mS} \cdot \mathrm{cm}^{-1}, 3.74 \mathrm{mS} \cdot \mathrm{cm}^{-1}$, $5.0 \mathrm{mS} \cdot \mathrm{cm}^{-1}$, and $6.25 \mathrm{mS} \cdot \mathrm{cm}^{-1}$, where the plants had calcium foliar-applied, had an EC of $3.11 \mathrm{mS} \cdot \mathrm{cm}^{-1}, 8.11 \mathrm{mS} \cdot \mathrm{cm}^{-1}$,
A

\section{Experiment $\mathrm{A}$}

Relation between seed production and fertilizer level
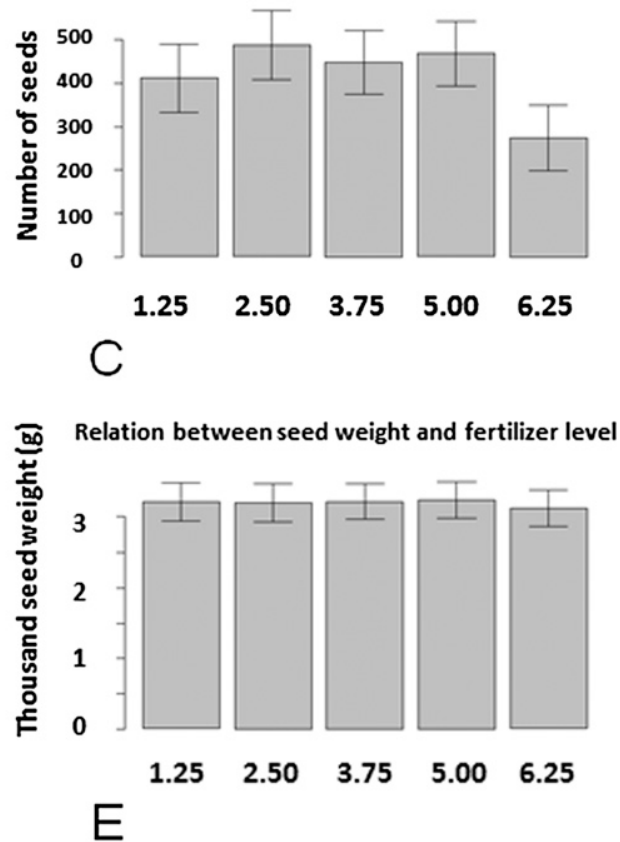

Relation between biomass production and fertilizer level

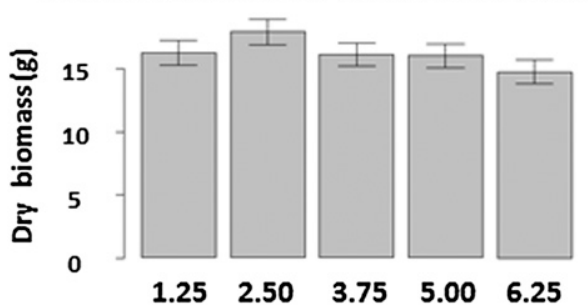

B Experiment B

Relation between seed production and fertilizer level
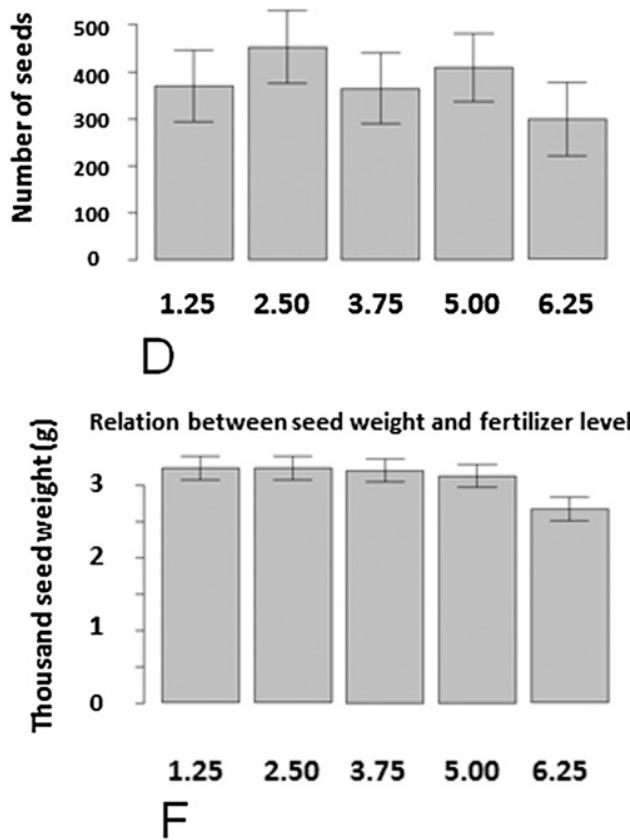

Relation between biomass production and fertilizer level

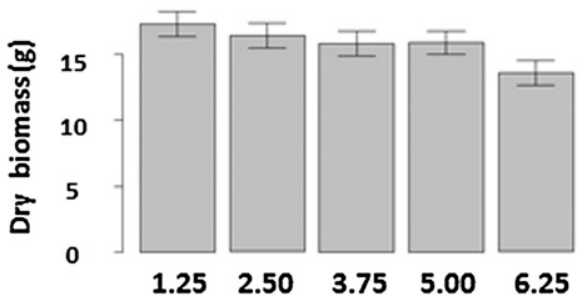

Fig. 1. Relation between seed production per plant and fertilizer concentration $(\mathrm{mS})$ and the $95 \%$ confidence interval for the two experiments. (A-B) In Expt. A, the seed production at the fertilizer concentration of $6.25 \mathrm{mS} \cdot \mathrm{cm}^{-1}$ was significantly lower than the other measurements. (C-D) Relation between thousand seed weight and fertilizer concentration $\left(\mathrm{mS} \cdot \mathrm{cm}^{-1}\right)$ and the $95 \%$ confidence interval for the two experiments. In Expt. B, the seed weight at the fertilizer concentration of $6.25 \mathrm{mS} \cdot \mathrm{cm}^{-1}$ was significantly lower compared with the other measurements. (E-F) Relation between dry biomass production and fertilizer concentration $\left(\mathrm{mS} \cdot \mathrm{cm}^{-1}\right)$ and the $95 \%$ confidence interval for the two experiments. In both experiments, the biomass production at the fertilizer concentration of $6.25 \mathrm{mS} \cdot \mathrm{cm}^{-1}$ was significantly lower than the rest. 


\section{Experiment $\mathrm{A}$}
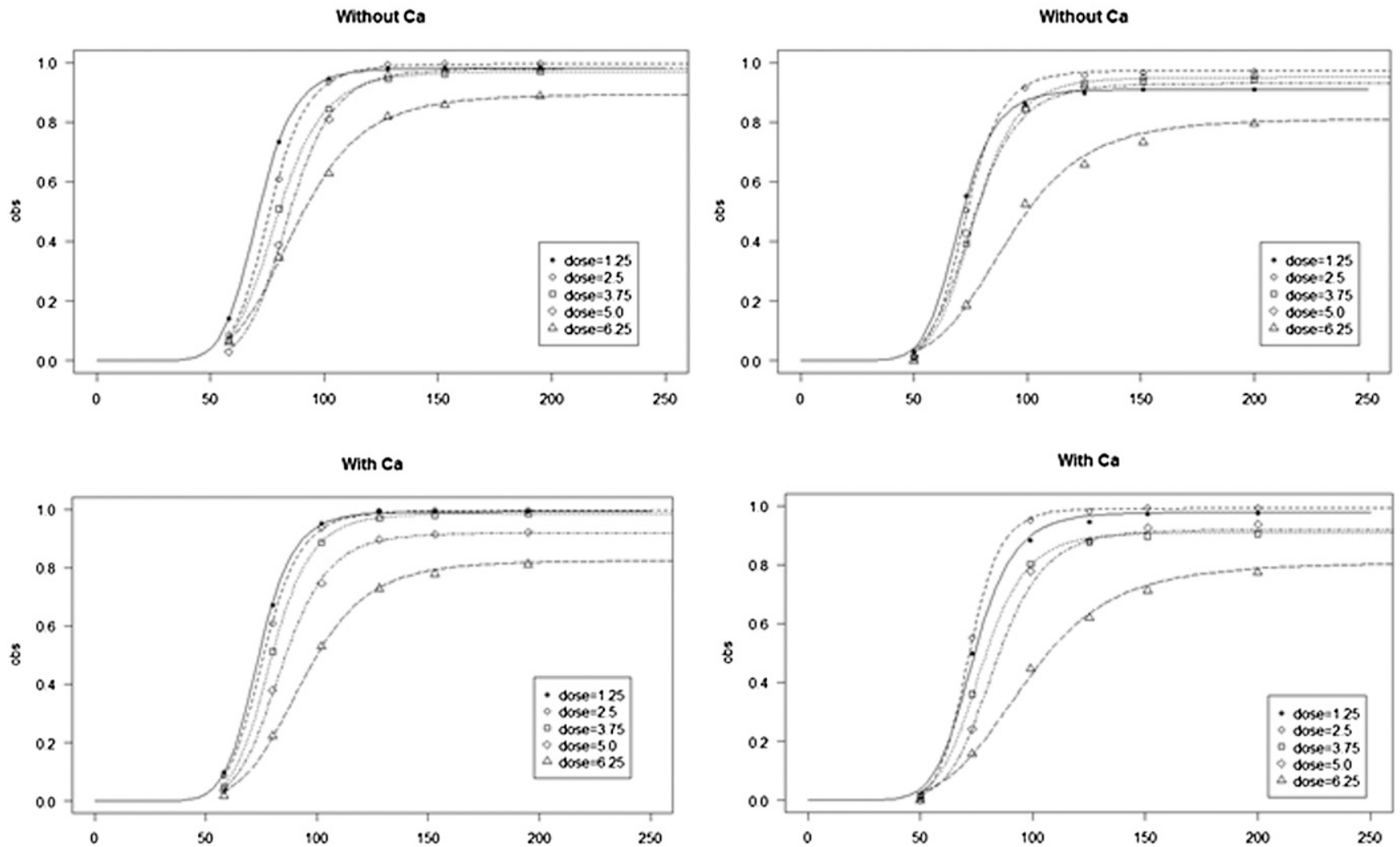

\section{Experiment B}

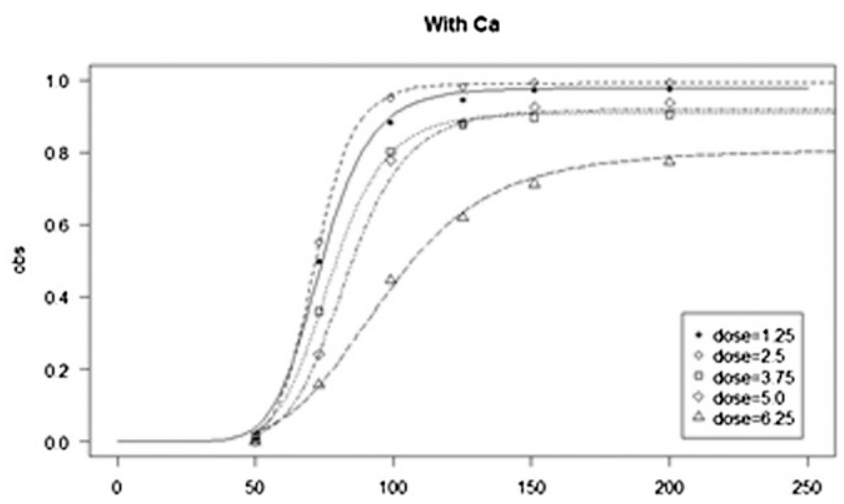

Fig. 2. Germination curves of seed lots from plants treated with different fertilizer levels $\left(\mathrm{mS} \cdot \mathrm{cm}^{-1}\right)$ in Expts. A and B.

Table 1. Treatments [fertilizer level measured as electrical conductivity $\left(\mathrm{mS} \cdot \mathrm{cm}^{-1}\right)$ and with and without applied foliar-applied calcium] and estimates of parameters of the germination model (1) for Expts. $\mathrm{A}$ and $\mathrm{B}{ }^{\mathrm{z}}$

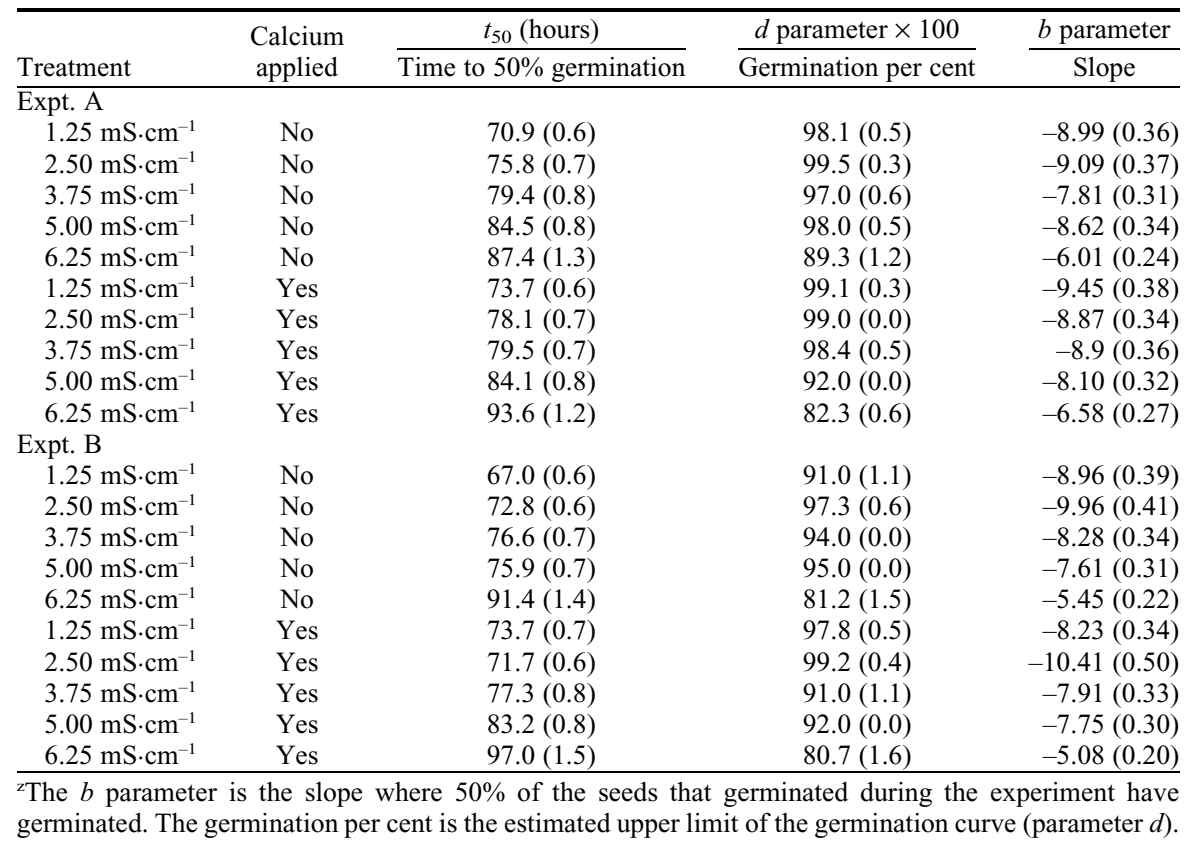

$14.74 \mathrm{mS} \cdot \mathrm{cm}^{-1}, 15.70 \mathrm{mS} \cdot \mathrm{cm}^{-1}$, and 22.00 $\mathrm{mS} \cdot \mathrm{cm}^{-1}$, respectively.

Expt. B. The mean number of flower heads was 3.99 per plant $(\mathrm{SD}=1.48)$. The number of flower heads was not significantly affected by fertilizer level and foliar-applied calcium. The mean number of seeds produced was 380 seeds per plant $(\mathrm{SD}=220)$. The total seed production was not significantly affected by fertilizer dose or applied calcium (Fig. 1B). The thousand seed weight was significantly affected by fertilizer dose $(P=0.000002)$ (Fig. 1D), but there was no significant effect of applying calcium. An ANOVA showed that the reduced model (without calcium) described the data just as good as the model including calcium. Homogeneity of variance was checked based on plots of standardized residuals against predicted values by use of residual plots and QQ normal plots of raw residuals. Calculation of the adjusted $P$ values between means of treatments revealed that the seed production at a fertilizer concentration of $6.25 \mathrm{mS} \cdot \mathrm{cm}^{-1}$ was significantly lower than the seed production at $1.25 \mathrm{mS} \cdot \mathrm{cm}^{-1}(P=0.049)$. The seed production at the other fertilizer levels did not significantly differ from each other (Fig. 1B). The seed weight at 6.25 $\mathrm{mS} \cdot \mathrm{cm}^{-1}$ was significantly lower than at the other concentration $(P=0.000)$ (Fig. 1D). The total dry biomass was significantly affected by dose (Fig. 1F). A dose of $6.25 \mathrm{mS} \cdot \mathrm{cm}^{-1}$ resulted in significantly lower biomass [hypotheses: $6.25-1.25=0(P=0.001) ; 6.25-$ $2.5=0(P=0.001) ; 6.25-3.75=0(P=$ $0.0089) ; 6.25-5=0(P=0.0047)]$. Also in Expt. B, seed germination percentage and speed were negatively affected by increasing fertilizer levels, and applied calcium did not have any significant effect on seed germination (Fig. 2; Table 1). 


\section{Discussion}

In the present study with Gerbera hybrida, foliar-applied calcium did not exert any effect on the explored parameters; neither yield parameters nor germination percentage and speed were affected. In Indian gooseberry (Emblica officinalis) (Shukla, 2011), calcium application reduced physiological problems like poor fruit set and improved yield and quality of the fruits.

We assumed that an increase in fertilizer level during seed set of Gerbera hybrida will increase biomass production and flower number and thus enhance seed production (Fig. 1A). However, in both experiments, the used fertilizer concentrations from 1.25 to 6.25 $\mathrm{mS} \cdot \mathrm{cm}^{-1}$ had no effect on the number of flower heads per plant. It negatively affected plant biomass production in both experiments at the highest fertilizer level (6.25 $\mathrm{mS} \cdot \mathrm{cm}^{-1}$ ) and it also reduced seed weight significantly in Expt. B (Fig. 1D). We also found that the seed production was significantly lower in Expt. A at the highest fertilizer dose compared with lower nutrient supply. These findings are in accordance with the guidelines for growers of Gerbera jamesonii hybrids (DEG, 2001), where a fertilizer concentration between $1.7 \mathrm{mS} \cdot \mathrm{cm}^{-1}$ and $2 \mathrm{mS} \cdot \mathrm{cm}^{-1}$ was recommended to produce uniform and attractive plants. However, in the present investigation, we wanted to study whether we could increase seed production and seed quality by increased fertilizer concentration during seed set. Our data showed that the seed production was rather constant in the investigated fertilizer dose interval, but a concentration of $6.25 \mathrm{mS} \cdot \mathrm{cm}^{-1}$ may be harmful for the plants resulting in lower seed production (Fig. 1A), lower biomass production (Fig. 1E-F), less seed weight (Fig. 1D), and reduced seed germination and germination speed (Fig. 2). A linear regression that takes into account the variance of the $T_{50}$ values (Draper and Schmidt, 1966) shows how they increase with increasing fertilizer level (Fig. 3). In field-grown Achillea, increasing plant biomass increased seed number and germination. Plant biomass was increased by applying fertilizer and fungicide (Allison, 2002). In sunflower, nitrogen (N) fertilization at different developmental stages of the plant affected seed number (8-fold change) with seed weight exhibiting a 1.6-fold increase with increasing $\mathrm{N}$ supply. In contrast to our study, no negative effects of high fertilizer application were reported; however, the range of tested fertilizer concentration and experimental condition is not comparable (Steer et al., 1984).

Although germination speed and percentages were negatively affected by increasing fertilizer levels in the present study, we obtained acceptable levels at all fertilizer levels. A low EC level resulting in satisfying germination is preferred in seed production as a result of reduced environmental impact of used fertilizers and lower production costs. Our results indicate that a low fertilizer concentration of 1.25 or $2.5 \mathrm{mS} \cdot \mathrm{cm}^{-1}$ would be a good choice for seed production resulting in seeds of good quality and at the same time save resources. Based on the two experiments, we suggest seed producers should not apply more fertilizer than corresponds to an $\mathrm{EC}$ value of $\approx 1.25 \mathrm{mS} \cdot \mathrm{cm}^{-1}$ and avoid nutrient concentrations of more than 3.75 $\mathrm{mS} \cdot \mathrm{cm}^{-1}$.

Apart from decreasing seed production and reduced germination, increasing fertilizer concentration may also increase the risk of fungi infections (Cwalina-Ambroziak et al., 2012; Lecompte et al., 2013). In our experiments, we observed that the highest fertilization level resulted in diseased plants with symptoms of Botrytis cinerea infection (gray mildew). Few plants wilted and were removed.

The analysis of samples of nutrient solution squeezed out of the soil at the end of the experiments revealed that the soil in all pots accumulated fertilizer. EC in the samples documented that the nutrients accumulated during the growth period in all pots even when we used the lowest nutrient solution. The nutrient accumulation in pots irrigated with the highest nutrient solution resulted in extremely high values $\left[23.2 \mathrm{mS} \cdot \mathrm{cm}^{-1}\right.$ (without calcium) and $22.0 \mathrm{mS} \cdot \mathrm{cm}^{-1}$ (with calcium)], which probably had a phytotoxic effect on the plants and affected the seed quality. Gerbera is classified as a moderately sensitive species to EC levels of nutrient solution (Sonneveld, 1988; Sonneveld et al., 1999). Sonneveld et al. (1999) examined the effect of growing Gerbera cultivar Beauty in soilless culture with the values of EC between 1.8 and $3.7 \mathrm{dS} \cdot \mathrm{m}^{-1}$ and sodium and chlorine concentrations between 0 and 16 $\mathrm{mmol} \cdot \mathrm{L}^{-1}$. Total flower weight $\left(\mathrm{kg} \cdot \mathrm{m}^{-2}\right)$ was only moderately affected by increasing EC/ $\mathrm{NaCl}$ levels and vase life was not significantly affected by salinity treatments. In the present study, we chose increasing EC levels to find the optimal fertilizer level for highest seed set and seed quality. The high EC values were included to estimate at which nutrient level the seed quality became negatively affected. It would have been valuable if we also had included a treatment with a lower EC value like $0.75 \mathrm{mS} \cdot \mathrm{cm}^{-1}$ to improve the estimate of the optimal EC level from a curved function for seed production and quality parameters. The seed production and germination results were obtained using a fertilizer composition recommended from a commercial seed producer and were based on grower recommendations for potted Gerbera hybrida (DEG, 2001). Other fertilizer compositions might have given different results regarding seed production and germination. It is well documented that high osmotic pressure in the germination solution delays germination as exemplified by Helianthus annuus (Kaya et al., 2006). Further studies are needed to explore whether a different nutrient content in the obtained Gerbera hybrida seeds is the reason for the observed decreasing germination with increasing EC during seed production. Perhaps leakage of endogenous solutes from the seeds in the present study had an influence on osmotic pressure of the germination solution as discussed by Bliss et al. (1986) for barley cultivars.

\section{Experiment $\mathrm{A}$}

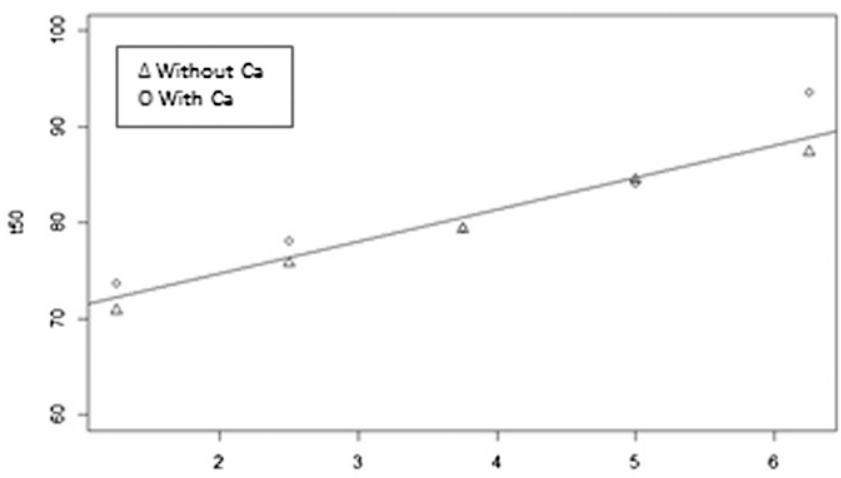

Fertilizer concentration $\left(\mathrm{mS} \mathrm{cm}^{-1}\right)$

\section{Experiment $\mathrm{B}$}

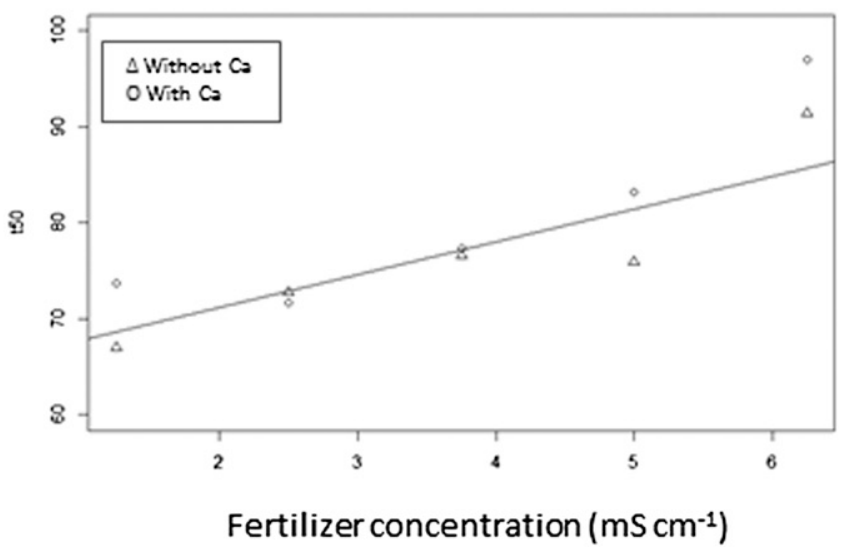

Fig. 3. Linear regressions show how time to $50 \%$ germination increased with increasing fertilizer level. 


\section{Literature Cited}

Albino-Garduño, R., H.A. Zavaleta-Mancera, L.M. Ruiz-Posadas, M. Sandoval-Villa, and A. Castillo-Morales. 2008. Response of Gerbera to calcium in hydroponics. J. Plant Nutr. 31:91-101.

Allison, V.J. 2002. Nutrients, arbuscular mycorrhizas and competition interact to influence seed production and germination success in Achillea millefolium. Funct. Ecol. 16:742-749.

Bliss, R.D., K.A. Platt-Aloia, and W.W. Thomson. 1986. Osmotic sensitivity in relation to salt sensitivity in germinating barley seeds. Plant Cell Environ. 9:721-725.

Carpenter, W.J., E.R. Ostmark, and J.A. Cornell. 1995. Temperature and seed moisture govern germination and storage of Gerbera seed. HortScience 30:98-101.

Cwalina-Ambroziak, B., J. Wierzbowska, M Damszel, and T. Bowszys. 2012. The effect of mineral fertilization on achenes yields and fungal communities isolated from the stem of milk thistle Silybum marianum (L.). Gaertner. Acta Scient. Polo. Hort. Cultus 11:157-168.

DEG. 2001. Standarddyrkningsvejledning for Gerbera jamesonii hybrider (Potte-Gerbera). Dansk Gartneri, Copenhagen, Denmark.

Draper, N.R. and H. Schmidt. 1966. Applied linear regression. 2nd Ed. John Wiley and Sons, Inc., New York, NY.
Dufault, R.J., T.L. Phillip, and J.W. Kelly. 1990 Nitrogen and potassium fertility and plant populations influence field production of gerbera. HortScience 25:1599-1602.

Hansen, H.V. 1999. A story of the cultivated Gerbera. The New Plantsman 6:85-95.

Hothorn, T., F. Bretz, and P. Westfall. 2008. Simultaneous inference in general parametric models. Biometrical J. 50:346-363.

ISTA. 2011. International rules for seed testing. Germination tests. International Seed Testing Association, Basserdorf, Switzerland.

Kaya, M.D., G. Okçu, M. Atak, Y. Cikili, and Ö. Kolsarici. 2006. Seed treatments to overcome salt and drought stress during germination in sunflower (Helianthus annuus L.). Eur. J. Agron. 24:291-295.

Lecompte, F., M.A. Abro, and P.C. Nicot. 2013. Can plant sugars mediate the effect of nitrogen fertilization on lettuce susceptibility to two necrotrophic pathogens: Botrytis cinerea and Sclerotinia sclerotiorum? Plant Soil 369:387-401.

Paradiso, R., S. De Pascale, F. Aprea, and G. Barbieri. 2003. Effect of electrical conductivity levels of nutrient solution on growth, gas exchanges and yield of two Gerbera in soilless system. Proceedings of IS on Greenhouse Salinity. Eds: A. Pardossi et al. Acta Hort 609:165-171.

Ritz, C., C.B. Pipper, and J.C. Streibig. 2013. Analysis of germination data from agricultural experiments. Eur. J. Agron. 45:1-6.
Santos, K.M., P.R. Fisher, and W.R. Argo. 2009. Stem versus foliar uptake during propagation of Petunia $\times$ hybrida vegetative cuttings. HortScience 44:1974-1977.

Shukla, A.K. 2011. Effect of foliar application of calcium and boron on growth, productivity and quality of Indian gooseberry (Emblica officinalis). Indian J. Agr. Science 81:628632.

Sonneveld, C. 1988. The salt tolerance of greenhouse crops. Neth. J. Agr. Sci. 36:63-73.

Sonneveld, C., R. Bass, H.M.C. Nijssen, and J. de Hoog. 1999. Salt tolerance of flower crops grown in soilless culture. J. Plant Nutr. 22:1033-1048.

Steer, B.T., P.J. Hocking, A.A. Kortt, and C.M Roxburgh. 1984. Nitrogen nutrition of sunflower (Helianthus annuus L.): Yield components, the timing of their establishment and seed characteristics in response to nitrogen supply. Field Crops Res. 9:219-236.

Zerche, S., S.S. Verma, A. Ewald, and J. LudwigMüller. 2007. Quality of Primula vulgaris seeds as related to maturation level, mineral composition, abscisic acid content, storage duration and eluate conductivity. Seed Sci. and Tech. 35:111-128.

Zheng, Y., T. Graham, S. Richard, and M. Dixon. 2004. Potted Gerbera production in a subirrigation system using low-concentration nutrient solutions. HortScience 39:1283-1286. 